\title{
MUSEU DO IPIRANGA ${ }^{1}$
}

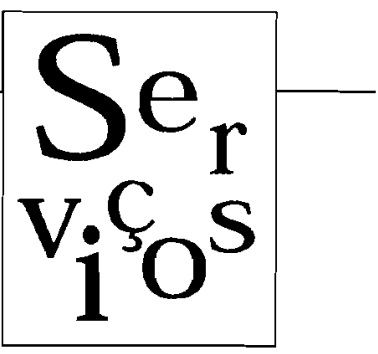

O Museu Paulista, um dos órgãos de integração da Universidade de São Paulo, caracteriza-se por ser uma instituição científica, cultural e educacional, voltada para a área de História da Cultura Material e, como tal, concentra suas atividades em torno de acervos. Estes proporcionam ao Museu a realização de atribuições específicas de um museu universitário: docência, pesquisa e prestação de serviços. $O$ conjunto destas atividades $-\mathbf{a}$ curadoria - busca a formação e ampliação das coleções, sua conservação, seu estudo e a divulgação do conhecimento gerado por meio de exposições, cursos e publicações.

Como museu histórico, dedica-se ao estudo específico da organização da sociedade brasileira, implementando três linhas de pesquisa: Cotidiano e Sociedade; Universo do Trabalho e História do Imaginário.

Para entendermos o Museu Paulista, conhecido também como Museu do Ipiranga, é necessário conhecermos a história do edifício que o abriga, e a sua própria trajetória histórica enquanto instituição museológica.

O edifício, no qual o Museu foi instalado, é o memorial concebido para assinalar o local da proclamação da Independência, a 7 de setembro de 1822. A idéia da construção de um monumento no sítio do Ipiranga surgiu logo após o acontecimento, sendo elaborados vários projetos no decurso de mais de cinco décadas. No entanto, o projeto somente se concretizou nos inícios da década de 80 do século passado, concorrendo para isso o desenvolvimento da própria Província de São Paulo, favorecida pela expansão cafeeira. Foram instituídas as loterias do Ipiranga para obtenção de recursos financeiros para a sua construção. A primeira loteria correu em fevereiro de 1881 , possibilitando a colocação da pedra fundamental a 10 de outubro de 1882, com grande solenidade. A fiscalização das obras ficou sob a responsabilidade de duas comissões, uma em São Paulo e outra na Corte.

Coube ao arquiteto italiano Tommazzo Gaudenzio Bezzi a concepção do projeto e a orientação da construção do edifício-monumento, que levou cinco anos para ser erguido, de 1885 a 1890 . O Monumento foi dado por concluído sem que tivessem sido construídas as galerias laterais previstas. Luigi Pucci foi o empreiteiro da obra, que contou com o trabalho dos operários e artesãos italianos. As técnicas construtivas e os mate-

\section{A AUTORA}

\section{Mioko Makino}

Diretora Técnica da Divisão de Difusão Cultural e Professora do Museu Paulista da USP. 
riais empregados significaram uma inovação para a cidade de São Paulo, acostumada às construções em taipa de pilão. O estilo palaciano, com os arcos e colunas, serviu de modelo para outras construções, que surgiram em São Paulo na virada para o século XX.

Desde o início da instalação das coleções no edifício, percebeu-se que os três planos eram insuficientes para abrigar uma instituição de pesquisa do porte do Museu Paulista, com laboratórios, reservas técnicas, salas de exposição, biblioteca etc. $O$ subsolo, aos poucos, foi, por isso, sendo ocupado, após a retirada do entulho. As últimas intervenções ocorreram entre $1994 \mathrm{e}$ 1995, quando alguns espaços foram recuperados, e estão ocupados atualmente por exposições temáticas.

Ocorreram significativas intervenções no edifício, ao longo deste século. Tais como a ornamentação interna para as comemorações do I Centenário da Independência e, de 1995 a 1997, a reforma dos telhados, das torres e da rede elétrica, quando foram também executadas a pintura interna, a restauração das portas, dos ornamentos e das pinturas da Sanca (parte arquitetônica do teto).

$\mathrm{O}$ edifício-monumento foi tombado pelos órgãos de preservação do patrimônio historico, artístico e cultural de todas as instâncias, no nível federal, estadual e municipal, como integrante do Parque da Independência.

Muitas foram as discussões na Assembléia Legislativa Provincial sobre a ocupação do Monumento. Pensou-se inicialmente na instalação de uma escola técnica, mas esta não se efetuou, por problemas de localização e insalubridade. De 1890 até agosto de 1893, o edifício ficou sem determinação de uso e somente nesta última data se estabeleceu que as coleções do recém-criado Museu Paulista seriam alocadas neste espaço.

\section{MUSEU PAULISTA E SUA HISTÓRIA}

Os acervos do Museu Paulista se iniciaram a partir de uma coleção particular do Major Joaquim Sertório, o conhecido Museu Sertório, que em novembro de 1890 foi comprado pelo Conselheiro Francisco de Paula Mayrink, e por ele doado ao Governo do Estado. E de uma outra coleção pública da Associação do Progresso da Província de São Paulo que, em 11 de julho de 1877 , inaugurou o Museu Provincial.

A preocupação do Museu Provincial não era a formação de coleções, mas sim a promoção de atividades culturais. Elas tiveram pouca duração e sua coleção ficou depositada numa das salas do Palácio do Governo.

O Museu Sertório, pelo contrário, chamava a atenção dos viajantes estrangeiros por abrigar em suas coleções as mais variadas peças. Englobava coleções de zoologia, botânica, mineralogia, artefatos indígenas e peças arqueológicas, além de objetos de personalidades históricas e alguns quadros.

Em dezembro de 1890, surgiu, portanto, o Museu do Estado, resultado da unificação destas duas coleções, cuja administração ficou a cargo da Comissão Geográfica e Geológica do Estado de São Paulo, criada em 1886 e presidida, na ocasião, por Orville Derby.

A instalação do Museu deu-se em abril de 1891, quando o Presidente do Estado, Américo Brasiliense, indicou para a direção do Museu Albert Löefgren, e nomeou os auxiliares Guilherme Friedenreich e Alexander Hummel, os quais já conheciam as coleções do Museu Sertório.

Em agosto de 1893, a Lei n. 192 determinou o uso do Monumento do Ipiranga como sede do Museu, com a transferência das coleções da Comissão Geográfica e Geológica, e a Lei n. 200 autorizou a reor- 
ganização do Museu, tendo como objetivo "servir de instrução para o povo e de instrumento de investigação científica para o Estado". Expressava-se a característica do Museu como "museu zoológico, antropológico, destinando-se à América do Sul em geral e ao Estado de São Paulo em particular". O Museu Panlista, em seus inícios, possuía coleções de zoologia, mineralogia, botânica, arqueologia, peças indígenas e objetos históricos, constituindo-se em um Museu de História Natural, que procurava abranger todo o conhecimento humano.

Em janeiro de 1894, nomeou-se Hermann von Ihering como diretor, De fevereiro a maio transferiram-se as coleções para o Monumento da Independencia e, em julho, aprovava-se o Regulamento do Museu.

Em cerimônia bastante concorrida, Bernardino de Campos, Presidente de Estado, inaugurou solenemente o Museu Paulista no edif́́cio-monumento a 7 de setembro de 1895, entregando-o à visitação pública, Nesse mesmo ano, iniciou-se a publicação da Revista do Museu Paulista, que até 1922 continha artigos de Botânica, Zoologia, Antropología e História, seguindo os objetivos de um Museu de História Natural.

Em 1917, assumiu a direção do Museu Afonso d'Escragnolle Taunay, que preparou o edifício para os festejos do Centenário da Independência, realizando seu projeto de ornamentação, com a execução de pinturas e esculturas por artistas contratados. Em 1922, além de abrir oito salas de exposição de História, criou a Seção de História Nacional e lançou o primeiro tomo de Anais do Museu Paulista, para publicação de assuntos de História e Etnografia. Durante sua gestão, até 1945, encomendou pinturas, coletou objetos e, de maneira geral, ampliou as coleções históricas; por outra parte, favoreceu a transferência de coleções de Mineralogia, Botânica e Zoologia para instituições afins,

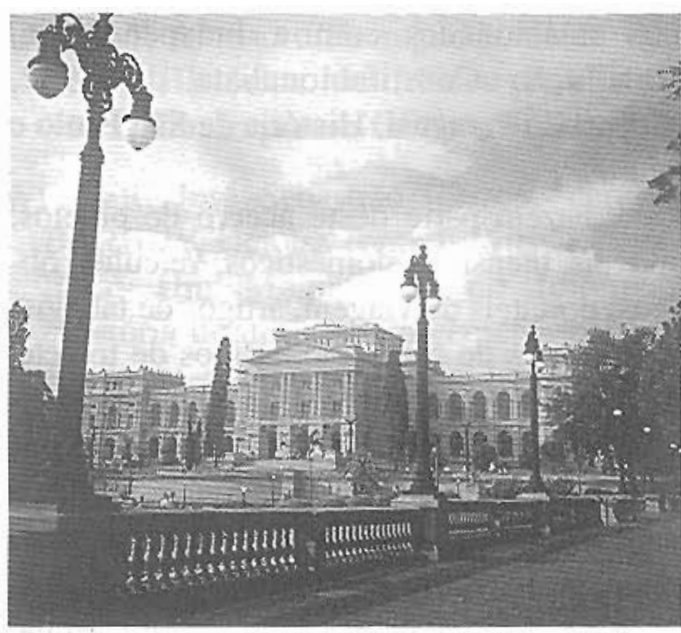

Vista da fachada do edifício do Museu Paulista e do Parque da Independênciá.

permanecendo no Museu as coleções de História e de Etnografia.

Em 1934, com a criação da Universidade de São Paulo, o Museu Paulista tornou-se um instituto complementar. Sua integração definitiva à Universidade deu-se em 1963. En agosto de 1989, realizou-se a transferência das coleções de Arqueologia e Etnologia para o novo Museu de Arqueologia e Etnologia, na Cidade Universitária, permanecendo nesta Institurção os acervos de História.

\section{O ACERVO}

O Museu Paulista possui atualmente mais de 130 mil itens, incluindo-se os acervos do Museu Republicano Convenção de Itu, concentrados em três áreas; Objetos, Documentação Textual e Iconografia, abrangendo o períndo do século XVI até meados do XX. Destacam-se as coleções de Washington Luís, Prudente de Morais, Campos Sales, Bernardino de Campos, Pedro de Toledo, Alberto Santos Dumont, Tommazzo Gaudenzio Bezzi e de várias famílias paulistas e instituições. Existem conjuntos temáti- 
cos relacionados com a Independência, Revolução Constitucionalista de 1932, Guerra do Paraguai, História de São Paulo e outros.

Fazem parte deste acervo de objetos: móveis, utensílios domésticos, veículos, óbjetos portâteis de viagem, artigos de tabagismo, artigos de escritório, artigos de toalete, brinquedos, instrumentos de trabalho, fragmentos de constıução, armas de fogo e armas brancas, indumentária civil e militar e seus acessórios, instrumentos de precisão e de medição, equipamentos profissionais, peças de numismática, medalhística e filatelia.

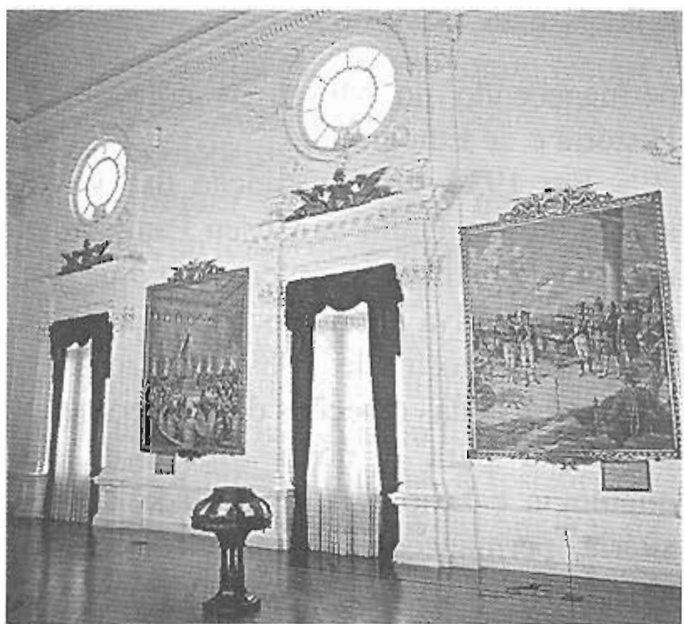

Vista parcial do Salão de Honra co Museu P̂aulista.

O acervo iconográfico compõe-se de pinturas, gravuras e desenhos, esculturas, coleções fotográficas, cartografía e material impresso. No conjunto das pinturas destacam-se Independencia ou Morte de Pedro Américo, Desembarque de Pedro Álvares na baía Cabrália de Oscar Pereira da Silva, Fundação de São Vicente de Benedito Calixto, Retirada do Cabo de São Roque de Henuique Bernardelli, entre outras. Dentre as coleções de fotografias, salienta-se a de Militão Augusto de Azevedo, composta de mais de 12 mil retratos executados entre
1862 e 1885 e dos registros mais antigos da cidade de São Paulo. Há uma significativa coleção de cartões postais referentes a cidades brasileiras, especialmente as do Estado de São Paulo.

Quanto à documentação textual, o Museu possui 640 metros lineares de documentos, reunidos em coleções e fundos de arquivos públicos e privados. No Arquivo Permanente do Museu estão os documentos produzidos entre os anos 1893 e 1963. Na coleção de correspondência destacam-se as cartas de D. Pedro I, José Bonifácio, Marquês de Valença; a correspondência $\mathrm{e} o$ material da Revolução Constitucionalista de 1932, de Tommazzo Gaudenzio Bezzi etc. Significativas são também a coleção João Batista de Campos Aguirra e as coleçōes dos jornais O Estado de S. Paulo (18751997) e Jomal da Tarde (1966-1997).

\section{ATIVIDADES DO MUSEU}

Em conformidade com o novo Regimento de 8 de maio de 1997, encontrase o Museu Paulista estruturado em três Divisões, que atendem às atividades de natureza administrativa, as de curadoria e acervo e as de difusão cultural. É extensão do Museu Paulista o Museu Republicano Convenção de ltu, sediado em Itu.

A Administração fomece o suporte necessário para que atividades de docência, pesquisa e serviços de extensão possam ser executadas.

Cabe à Divisão de Curadoria e Acervo as tarefas de ampliação, coleta, pesquisa, documentação, divulgação, conservação e restauração dos acervos, alérn das atividades de docência e de prestação de serviços. Os projetos de pesquisa, individuais ou instítucionais, visam, de um lado, à elaboração de dissertações e teses acadêmicas e, de ou- 
tro, à realização de pesquisas, que tenham por eixo os acervos a serem colocados à disposição do público através de cursos, exposições, publicações, bancos de dados informatizados, $C D$-Rom, vídeos etc.

Os trabalhos dos Laboratórios de Conservação e Restauração são direcionados para os acervos em exposição e a realização de vistorias periódicas e preventivas das coleções em reservas técnicas. São quatro as áreas de atuação: papel, pinturas, objetos e têxtil.

À Divisão de Difusão Cultural compete a execução de atividades que colocam o Museu em contato com o público: divulgação de cursos, palestras, seminários e eventos especiais; fornecimento de materiais para venda, doação e permuta; apoio a eventos educacionais e culturais; atendimento a solicitações de escolas, instituições e empresas.

O Museu Paulista proporciona estágios em suas diferentes áreas a interessados, principalmente a estudantes de graduação.

\section{Referências bibliográficas sobre o Museu e seu acervo:}

ELIAS, Maria José. Museu Paulista: memória e história. São Paulo: Departamento de História da Faculdade de Filosofia, Letras e Ciências Humanas da Universidade de São Paulo, 1996. (Tese de doutorado.)

Museu Paulista-USP. Às Margens do Ipiranga: 1890-1990. São Paulo: 1990. Patrocínio Cultural Bradesco. (Catálogo de Exposição.)

Suplemento Especial do Diário Oficial do Estado de São Paulo. O Museu Paulista da USP, vol. 107, n. 220, São Paulo, Sábado, 15 de novembro de 1997.8 p.
TAUNAY, Afonso d'Escragnolle. Guia da Seção Histórica do Museu Paulista. São Paulo: Imprensa Oficial, 1937.

WITTER, José Sebastião (direção geral), BARBUY, Heloísa (orgs.). Museu Paulista: Um Monumento no Ipiranga (História de um edifício centenário e de sua recuperação). São Paulo: Federação e Centro das Indústrias do Estado de São Paulo, 1997.

\section{Informações Sobre o Museu Paulista}

Visita às Exposições: de terças-feiras a domingo, das $9 \mathrm{~h}$ às $16 \mathrm{~h} 45$, inclusive aos feriados. Menores de 5 e maiores de 60 anos estão isentos de pagamento da entrada. Terceiro domingo de cada mês, a entrada é gratuita.

Biblioteca: contém cerca de 70 mil títulos, entre livros e periódicos, abrangendo História, Museologia, História da Cultura Material, Conservação e Restauração, Artes. Possui um núcleo de obras raras desde o século XVI. Funciona de segundas a sextas-feiras, das 8h às 17h. Ramal 2012.

Serviço de Documentação Textual e Iconografia: de segundas a sextas-feiras, das $9 \mathrm{~h}$ às $17 \mathrm{~h}$, com consulta previamente marcada. Ramais 2007 e 2035.

Serviço de Objetos: de segundas a sextas-feiras, com consultas marcadas previamente. Ramais: 2019 e 2021.

Laboratórios de Conservação e Restauração: de segundas a sextas-feiras, das $9 \mathrm{~h}$ às 16h45. Marcar com antecedência. Ramal 2015 (Pinturas, Objetos e Papel) e 2033 (Têxteis).

\section{Museu Paulista da USP}

Parque da Independência s/n Ipiranga

Tel.: 215-4588/215-4307/4145 
Fax: 215-4588 Ramais 2050 e 2051

Cx. Postal 42.503 CEP 04299-970

São Paulo-SP

e-mail: mp@usp.edu.br

Museu Republicano Convenção de Itu

Rua Barão de Itaim, 67

13300-000 Itu-SP

Exposição: de terça a domingo, das $9 \mathrm{~h}$ às $16 \mathrm{~h} 30$.
Visitas orientadas:

marcar com antecedência.

Biblioteca e Documentação: segundas a sextas-feiras, com horário marcado.

Tel./fax: (011) 783-0240
Resumo: O Museu do Ipiranga ou Museu Paulista da USP é órgão de integração da Universidade de São Paulo e dedica-se ao estudo da História da Cultura Material da sociedade brasileira. $O$ edificio que 0 abriga foi construído como Monumento à Independência. Os acervos tiveram início na coleção do Museu Sertório, que em fins de 1890 foi comprado pelo Conselheiro Francisco de Paula Mayrink e por ele doado ao Governo do Estado. Subordinou-se à Comissão Geográfica e Geológica do Estado de São Paulo, de 1890 a 1893 . Em agosto de 1893, determinou-se o uso do Monumento como sede do Museu, com a transferência das coleções, e autorizou-se a sua reorganização. A 7 de setembro de 1895 foi inaugurado solenemente e aberto ao público. Em 1934, tornou-se um instituto complementar da Universidade de São Paulo, à qual se integrou definitivamente em 1963. O Museu Paulista possui mais de 130 mil peças concentradas em três áreas: Objetos, Documentação Textual e Iconografia, abrangendo o período do século XVI até meados do $X X$.

Palavras-chave: Museu do Ipiranga, Museu Paulista da USP, História, Antropologia, monumento à Independência
Abstract: The Museu do Ipiranga, or Museu Paulista da USP is a University of São Paulo integration organism and dedicates itself to the study of the History of the Brazilian society's Material Culture. The building that houses it was built as a Monument to Independence. The collections were began with the Museu Sertório collection, which was bought, at the end of 1890, by Counselor Francisco de Paula Mayrink, and donated by him to the State Government. The collection was subordinated to the State of São Paulo Geographical and Geological Commission between 1890 and 1893. In August 1893, it was determined that the Monument would be used as the Museum's headquarters. The collections were transferred and reorganization was authorized. The museum was solemnly inaugurated and open to the public on September $7^{\text {th }} 1895$. In 1934, it became a University of São Paulo complementary institute, and it was finally incorporated to it in 1963. The Museu Paulista owns more than 130 thousand pieces concentrated in three areas: Objects, Textual Documentation and Iconography, covering the period ranging from the $16^{\text {th }}$ to mid $20^{\text {th }}$ Centuries.

Key words: Museu Paulista da USP, Museu do Ipiranga, History, Anthropology, monument to Independence 